\title{
Flexible thermoplastic starch films functionalized with copper particles for packaging of food products
}

\author{
Olivia V. López ${ }^{1 *}$, María E. Villanueva ${ }^{2,3,4^{*}}$, Guillermo J. Copello 2,3 and Marcelo A. Villar ${ }^{1,5}$
}

\begin{abstract}
Biodegradable films based on thermoplastic corn starch (TPS) and copper particles with antimicrobial capacity were developed. Copper nanoparticles (Cu) and silica coated copper microparticles ( $\mathrm{Si}-\mathrm{Cu}$ ) in the range of 0.25 to 5\% were used. Composite films were obtained by melt-mixing and subsequent thermo-compression. Particles distribution within TPS matrix and the presence of some pores and cracks, induced by Si-Cu particles, was evaluated by SEM. The presence of both fillers gave composite films a brown pigmentation and decreased their transparency; these effects were more pronounced at higher particles concentrations. Regarding mechanical properties, copper particles at 1 and 5\% acted as reinforcing agents increasing the maximum tensile strength but their presence lead to a decrease in elongation at break, affecting films ductility. Composites inhibited the growth of Gram+ and Gram- bacteria, demonstrating their antimicrobial capacity. Copper effectively migrated to a simulant of aqueous foods and naked particles concentration in the simulant medium resulted higher than the minimum inhibitory concentration for bacteria. The characteristics and properties of developed composite films make them an interesting material for food primary packaging, mainly for meat fresh products.
\end{abstract}

Keywords: Active films, Thermoplastic starch, Copper particles, Antimicrobial packaging

\section{Introduction}

Food spoilage caused by microorganisms can easily occur in a short time unless the proper precautions are taken. Despite the processing of raw food extend their shelf life, processed food generally needs to be packaged for protection, containment, convenience and communication [1]. These packaging characteristics are considered passive since they merely act as a barrier between the packaged food and the external environment. Currently, the food industry has been tremendously changing to innovate packaging, to cope with global trends, technological advances, and consumer preferences [2]. Within this context, active

\footnotetext{
*Correspondence: olivialopez@plapiqui.edu.ar; mevillanueva@ffyb.uba.ar ${ }^{1}$ Planta Piloto de Ingeniería Química, PLAPIQUI (UNS-CONICET), Camino La Carrindanga Km. 7, 8000 Bahía Blanca, Argentina

${ }^{2}$ Departamento de Química Analítica y Fisicoquímica, Facultad de Farmacia y Bioquímica, Universidad de Buenos Aires (UBA), Junín 956, C1113AAD

Buenos Aires, Argentina

Full list of author information is available at the end of the article
}

packagings are needed since they provide desirable advantages, such as antioxidant or antimicrobial activity, enhancing packaging performance [3, 4].

Several active packaging materials are discussed in literature, especially those regarding with antimicrobial activity. The main strategies to achieve this capacity are: i) the inclusion of sachets/pads that contain volatile antimicrobial compounds, ii) the incorporation of volatile and nonvolatile antimicrobial compounds directly into the structure of the polymers, iii) the application of a coating or adsorbing antimicrobial compound onto the surfaces of the polymers in contact with a foodstuff, iv) the immobilization of antimicrobial agents in polymers by methods such as ion or covalent linkages, v) the application of polymers, such as chitosan, that can inherently act as antimicrobial compounds, and vi) the incorporation of antimicrobial nanoparticles/microparticles [5].

\section{Springer Open}

(๑) The Author(s). 2020 Open Access This article is licensed under a Creative Commons Attribution 4.0 International License, which permits use, sharing, adaptation, distribution and reproduction in any medium or format, as long as you give appropriate credit to the original author(s) and the source, provide a link to the Creative Commons licence, and indicate if changes were made. The images or other third party material in this article are included in the article's Creative Commons licence, unless indicated otherwise in a credit line to the material. If material is not included in the article's Creative Commons licence and your intended use is not permitted by statutory regulation or exceeds the permitted use, you will need to obtain permission directly from the copyright holder. To view a copy of this licence, visit http://creativecommons.org/licenses/by/4.0/. 
Particles inclusion in food packaging has been done not only to confer antimicrobial activity to the material but also to improve the mechanical and barrier properties [6-8]. Some authors reported the use of ionic doped glass microparticles as antimicrobial compounds [9-11]. However, these additives are generally toxic at low concentrations and their use in antimicrobial packaging can cause great concern for consumers. Thus, application of antimicrobial compounds that present thermal stability and high antimicrobial activity has been a great expectation for scientific and industrial studies [12]. Despite copper microparticles have been described as an efficient antimicrobial agent [13, 14], they have not been applied to food packaging yet. Furthermore, copper micro and nanoparticles were classified as non-toxic and moderate toxic respectively [15]. Besides, when particles migrate to the food surface they transform in the $\mathrm{Cu}$ ionic form either in the food matrix or in the gastrointestinal tract since they are not stable in an acidic media. In these cases, the European Food Safety Authority [16] on the risk assessment of nanotechnologies in food and the feed chain suggested that the hazard identification and hazard characterisation can rely on data for the non-nanoform substance. The World Health Organization [17] established an acceptable copper intake of $10-12 \mathrm{mg} /$ person/day with a natural intake of $1-2 \mathrm{mg} /$ person/day. Based on this data, the European Food Safety Authority [18] concluded that an acceptable upper exposure limit was $0.15 \mathrm{mg} / \mathrm{kgbw} /$ day, with exposure limits of $0.2 \mathrm{mg} /$ $\mathrm{kgbw} /$ day and $0.15 \mathrm{mg} / \mathrm{kgbw} /$ day for adults and children, respectively [19].

On the other hand, the negative environmental impact of plastic packaging materials derived from petroleum, have motivated several studies on natural and biodegradable food packaging [20-22]. In this sense, starch is a promising alternative because of its low cost, wide availability, and functionality. Besides, starch can be converted into a thermoplastic material by processing under high temperature and shear stress in the presence of plasticizers [23]. Recently, several research papers of starch active films for food packaging have been published [24-26].

The aim of this work was to obtain active films based on thermoplastic corn starch (TPS) with nude and silica-coated copper particles, which could extend the shelf-life of perishable food products. Composite materials were structurally characterized by Scanning Electron Microscopy (SEM) and Diamond Attenuated Total Reflectance - Fourier Transform Infrared Spectroscopy (ATR-FTIR). Besides, their optical and mechanical properties, copper release, and antimicrobial capacity against Gram- negative and Gram-positive bacteria were also tested.

\section{Experimental}

\section{Materials}

Copper (II) chloride and hydrazine were purchased from Biopack (Buenos Aires, Argentina). Sodium silicate was purchased from Sigma-Aldrich. Staphylococcus aureus ATCC 29213 was generously provided by the Microbial Culture Collection of Facultad de Farmacia y Bioquímica (CCM 29), University of Buenos Aires, and Escherichia coli wild type was isolated from a hospital environment. All microorganisms were grown at $35^{\circ} \mathrm{C}$ for $24 \mathrm{~h}$ on Luria-Bertani (LB) medium (Britania, BA, Argentina).

Native corn starch was provided by Misky-Arcor (Tucumán, Argentina) with an amylose content of $23.9 \pm 0.7 \%$, previously characterized by López et al. [27] This polysaccharide presents a weight-average molecular mass of $2 \times 10^{4} \mathrm{~g} / \mathrm{mol}$ for amylose and $2 \times 10^{5}$ to $1 \times 10^{6}$ $\mathrm{g} / \mathrm{mol}$ for amylopectin [28]. Starch moisture content was $10.5 \%$, determined gravimetrically. Analytical grade glycerol (Anedra, Argentina) was used as starch plasticizer.

\section{Copper particles preparation}

$\mathrm{Cu}$ particles preparation was carried out by reducing a copper salt solution $\left(\mathrm{CuCl}_{2}, 0.05 \mathrm{M}\right)$ with hydrazine $(5 \%$ $\mathrm{w} / \mathrm{v})$. The stabilizing agent was a $1 \%(\mathrm{w} / \mathrm{v})$ aqueous starch solution. Briefly, equal volumes of starch and copper salt solutions were mixed, then the $\mathrm{pH}$ was adjusted to 10 using concentrated ammonia solution (37\%). Hydrazine solution $(2 \mathrm{~mL})$ was added to the starch/copper chloride solution and left in a bath at $90{ }^{\circ} \mathrm{C}$ until the blue transparent solution had changed to pale yellow after reducing agent treatment, and then changed to the characteristic red color, upon heating, indicating the formation of $\mathrm{Cu}$ particles. These particles were washed three times with $1 \%$ starch solution. The reduction reaction can be expressed as:

$$
\begin{aligned}
& 2 \mathrm{Cu}\left(\mathrm{NH}_{3}\right)_{2}{ }^{2+}+\mathrm{N}_{2} \mathrm{H}_{4}+4 \mathrm{OH}^{-} 2 \mathrm{Cu}+\mathrm{N}_{2} \\
& \quad+4 \mathrm{NH}_{4} \mathrm{OH}
\end{aligned}
$$

\section{Silica coated Cu particles}

Silica coating was performed in order to improve $\mathrm{Cu}$ particles stability. An inverse emulsion system was used to this end. The organic phase was obtained by mixing $60.0 \mathrm{~mL}$ of ethanol and $2.0 \mathrm{~g}$ of Tween 20 . The aqueous phase was prepared by mixing $1 \mathrm{~mL}$ of sodium silicate solution $\left(2.3 \times 10^{-2} \mathrm{~g} / \mathrm{mL}\right)$ with $10.0 \mathrm{~mL}$ of an aqueous suspension of $\mathrm{Cu}$ particles $(18.7 \mathrm{mM} \mathrm{Cu})$. The aqueous phase was added dropwise to the organic phase and left with agitation for $18 \mathrm{~h}$. After that time, it was centrifuged and washed three times with distilled water. This product was named $\mathrm{Si}-\mathrm{Cu}$. 


\section{Particles characterization}

Particles were characterized by scanning electron microscopy (SEM). Samples were dispersed over $3 \mathrm{M}$ aluminum conductive tape stuck onto stubs by using an air flow. Then, they were coated with gold in a sputter coater SPI, and observed in a LEO 40X VP Scanning Electron Microscope (Jena, Germany), operated at 10 $\mathrm{kV}$. The topographical characteristics of particles were obtained from secondary electron signal. On the other hand, particles size distribution was studied using a Horiba Partica LA-950 Laser Diffraction Particle Size Distribution Analyzer (Kyoto, Japan).

\section{Films preparation}

Mixtures of native corn starch, glycerol $(35 \% \mathrm{w} / \mathrm{w})$, and copper particles $(0,0.25,0.50,0.75,1$, and $5 \% \mathrm{w} / \mathrm{w})$ were prepared. Particles was premixed with starch to achieve a good dispersion between both powders. Then, glycerol was added and samples were processed in an Atlas Laboratory mini mixer at $140{ }^{\circ} \mathrm{C}$ and $50 \mathrm{rpm}$ for $30 \mathrm{~min}$. These processing conditions were previously optimized in order to obtain a thermoplastic material [29]. Processed mixtures were removed from the mini mixer, triturated and conditioned at $25^{\circ} \mathrm{C}$ and $60 \%$ relative humidity (RH), in order to improve their proccesability. $\mathrm{RH}$ of the conditioning ambient was reached employing aqueous glycerol solutions at $72 \% \mathrm{w} / \mathrm{w}$. Films were obtained by thermocompression using a hydraulic press at $150 \mathrm{~kg} \mathrm{~cm}^{-2}$ and $140{ }^{\circ} \mathrm{C}$ for $6 \mathrm{~min}$. Composite films were named as TPS, $\mathrm{TPS} / \mathrm{Cu}_{\# \text {, }}$ and TPS $/ \mathrm{Si}-\mathrm{Cu}_{\#}$, where \# corresponds to the copper particles concentration in the composite.

\section{Films characterization}

Films color measurements were performed using a Hunter UltraScan XE (Reston, US) colorimeter in the transmittance mode. Parameter $\mathrm{L}^{*}, \mathrm{a}^{*}$, and $\mathrm{b}^{*}$ were recorded according to the CieLab scale. Luminosity range from $L^{*}=0$ (black) to $L^{*}=100$ (white), parameters range from: - $\mathrm{a}^{*}$ (greenness) to $+\mathrm{a}^{*}$ (redness), and $-\mathrm{b}^{*}$ (blueness) to $+b^{*}$ (yellowness).

Films transparency was determined from the absorption spectra $(400-700 \mathrm{~nm})$ recorded in a Shimadzu UV160 spectrophotometer (USA). Films were placed on the internal side of a glass spectrophotometer cell. Each sample was analyzed by triplicate. Films transparency was estimated using the procedure reported by Han and Floros [30].

Films homogeneity and appearance were examined by Scanning Electron Microscopy (SEM). Studies were performed in a JEOL JSM-35 CF (Japan), with a secondary electron detector. Films were cryo-fractured by immersion in liquid nitrogen, mounted on bronze stubs and coated with a gold layer, using an argon plasma metallizer (sputter coater PELCO 91000).
Diamond Attenuated Total Reflectance - Fourier Transform Infrared Spectroscopy (ATR-FTIR) of composite films were recorded using a Nicolet iS50 Advanced Spectrometer (Thermo Scientific). ATR-FTIR spectra were recorded with 32 scans and a resolution of $4 \mathrm{~cm}^{-1}$. All samples were previously dried for $24 \mathrm{~h}$ at $60^{\circ} \mathrm{C}$ to avoid water related bands interference.

Tensile tests were performed in an Instron 3369 universal mechanical testing system Instron, USA) using a crosshead speed of $2 \mathrm{~mm} / \mathrm{min}$ and a load cell of $50 \mathrm{~N}$. Ten test specimens $(13 \times 100 \mathrm{~mm})$ were assayed for each film formulation and stress-strain curves were calculated from load-displacement data. Maximum tensile strength $\left(\sigma_{\mathrm{m}}\right)$ and elongation at break $\left(\varepsilon_{\mathrm{b}}\right)$ were calculated according to ASTM D882-00 standard method.

\section{Antimicrobial activity assays}

Antimicrobial activity of composite films against Escherichia coli and Staphylococcus aureus was carried out using a modified Japanese Industrial Standards (JIS) test Z 2801. For this test, mentioned microorganisms were grown in LB medium for $24 \mathrm{~h}$. Then, they were diluted so that their concentration was $1.1 \times 10^{5} \mathrm{CFU} / \mathrm{mL}$ for $E$. coli and $2.3 \times 10^{5}$ $\mathrm{CFU} / \mathrm{mL}$ for $S$. aureus. As diluent for the bacteria suspension it was used a solution of LB medium diluted 500 times in sterile physiological solution. Each disk ( $0.5 \mathrm{~cm}$ diameter) of the different films was inoculated with $0.01 \mathrm{~mL}$ of the inoculum described above.

After $24 \mathrm{~h}$ of incubation at $35^{\circ} \mathrm{C}$, the viable microorganisms were counted by the plate count method. Decimal dilutions of the supernatant were made and spread on agar plates and incubated $24 \mathrm{~h}$ at $35^{\circ} \mathrm{C}$. After incubation, the colonies were counted. The results are presented as antimicrobial activity ( $(\mathrm{log})$ ) (Eq. 2) and percentage of bacterial reduction (D \%) (Eq. 3).

$$
\begin{aligned}
& R(\log )=\log (A)-\log (B) \\
& D \%=\frac{A-B}{A} \times 100
\end{aligned}
$$

where $A$ is the average of viable cells in the suspension exposed to TPS films and B is the average of viable cells in the suspension exposed to a TPS films with $\mathrm{Cu}$ or Si$\mathrm{Cu}$ particles.

\section{Copper release}

Disks of TPS/Cu$/ \mathrm{Cu}_{\#}$ and TPS/Si-Cu $\mathrm{Cu}_{\#}$ were accurately weighted (approximately $0.1 \mathrm{~g}$ ) and left in $1 \mathrm{~mL}$ of distilled water for $24 \mathrm{~h}$. The released copper was determined with a Buck Scientific VGP 210 Atomic Absorption Spectrophotometer (E. Norwalk, CT, USA) by the electrothermal atomization method using pyrolytic graphite tubes. 


\section{Results and discussion}

\section{Particles characterization}

Figure 1 shows size distribution and SEM micrographs of the synthesized copper particles. As it can be seen, images confirmed the spherical shape of the particles and evidenced that they form clusters, getting closer to each other. In the case of $\mathrm{Si}-\mathrm{Cu}$ samples it was found more free particles than in the case of $\mathrm{Cu}$ samples, probably due to the stabilizing effect of silica coating that avoid particles agglomeration. From SEM micrographs it was determined that the mean diameter of agglomerates of $\mathrm{Cu}$ particles varied between 63 and $160 \mathrm{~nm}$; meanwhile for Si-Cu particles the size ranged from 125 to $938 \mathrm{~nm}$. The higher size of $\mathrm{Si}-\mathrm{Cu}$ agglomerates could be associated to the higher $\mathrm{Si}-\mathrm{Cu}$ particles size, compared to that of $\mathrm{Cu}$ particles.

Both types of particles presented a monomodal size distribution. Histograms presented symmetrical gaussian curves with a median size of $2.53 \mathrm{~nm}$, a mean size of $2.97 \mathrm{~nm}$, and a mode of $2.79 \mathrm{~nm}$ for $\mathrm{Cu}$ particles; meanwhile for $\mathrm{Si}-\mathrm{Cu}$ particles these values were $76.21 \mathrm{~nm}$, $96.85 \mathrm{~nm}$, and $82.69 \mathrm{~nm}$, respectively. The differences in particles size determined by SEM and laser diffraction (LD) could be mainly attributed to the good dispersion of particles achieved during laser diffraction analysis, meanwhile in SEM observations particles were found as agglomerates. The equipment employed for LD has a high-output centrifugal pump to ensure consistent dispersion and flow of most of the particles. On the other hand, silica was homogeneously distributed around the copper particles forming a thin coating, which increased particles size without affecting their morphology. Taking into account results of LD, all copper particles presented nanometric sizes; meanwhile some particles coated with silica were micro-sized. Even though $\mathrm{Cu}$ particles presented nanometric sizes, the cluster formation could reduce their functionality. Similar observation was reported by Tolaymat et al. [31] and Din and Rehan [32].

\section{Films characterization}

All tested formulations allow obtaining films with homogeneous appearance and easy to handle. Visually, they were translucent and presented a significant pigmentation, which increased with particles concentration. Besides, this coloration was more marked for TPS/Si-Cu films.

SEM micrographs of TPS films containing $0.5 \%$ cooper particles as representative images of the other studied particle concentrations are shown in Fig. 2. The presence of starch unmelted granules was not observed in any of the studied samples, probably due to good materials processing by melt-mixing and thermo-compression. In addition, starch thermal plasticization was reached since no perpendicular channels to film surface produced by glycerol migration from the matrix, were observed [33]. Surface and cross-sections of TPS/Cu films resulted smooth and no pores or cracks were detected (Fig. 2a). Copper particles were not observed by SEM, probably due to their nanometric size and the good-dispersion within the matrix. This observation is a consequence of the good thermal processing that allowed a homogeneous distribution of $\mathrm{Cu}$ particles within the TPS. In the case of TPS/Si-Cu particles, several cracks were evidenced plus some loose particles, which were pulled-out from the matrix when films were cryo-fractured (Fig. 2b). The fact that this undesirable phenomenon was not detected in TPS/Cu composites but its presence in TPS/Si-Cu films could be attributed to a lower compatibility of coated particles with the starch matrix than naked ones. On the other hand, $\mathrm{Si}-\mathrm{Cu}$ particles which remained inside the matrix were not visible at the employed magnifications during SEM observations, probably due to their small size.

FT-IR of the obtained films can be observed in the Supplementary information (Figure S1). In all the spectra, starch characteristic bands were present: a broad and strong band between 3726 and $3007 \mathrm{~cm}^{-1}$, corresponding
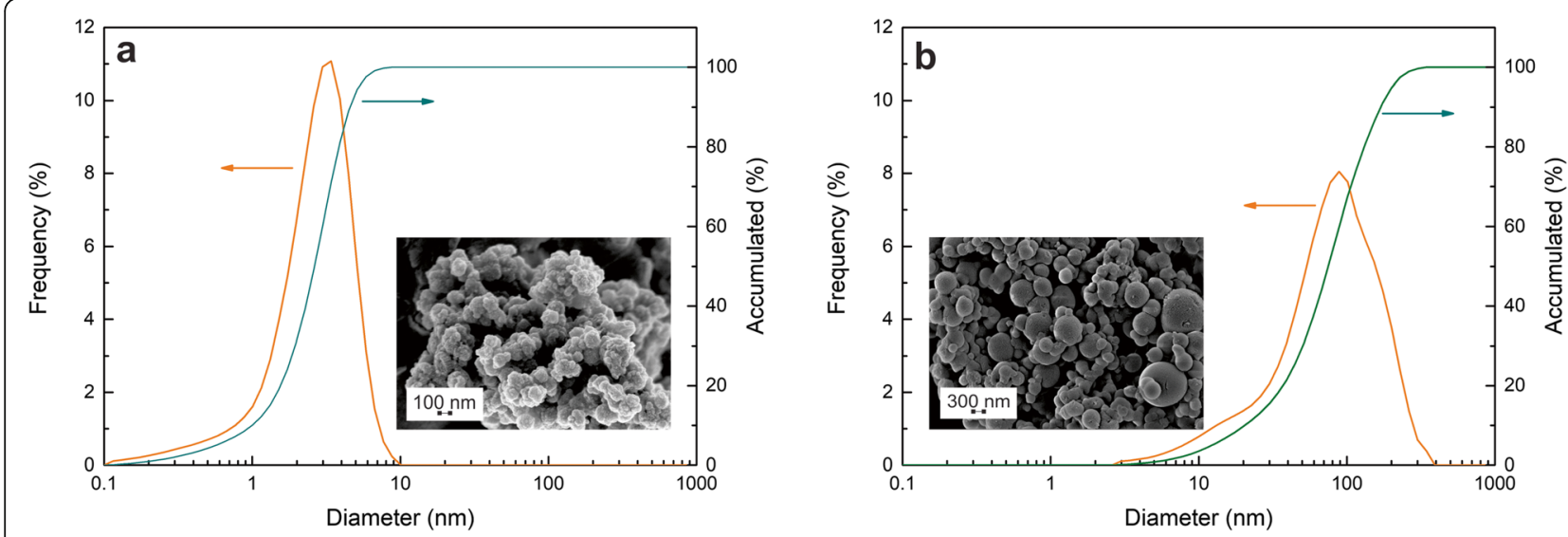

Fig. 1 Particles size distribution and SEM micrographs of: a) Cu and b) Si-Cu particles 

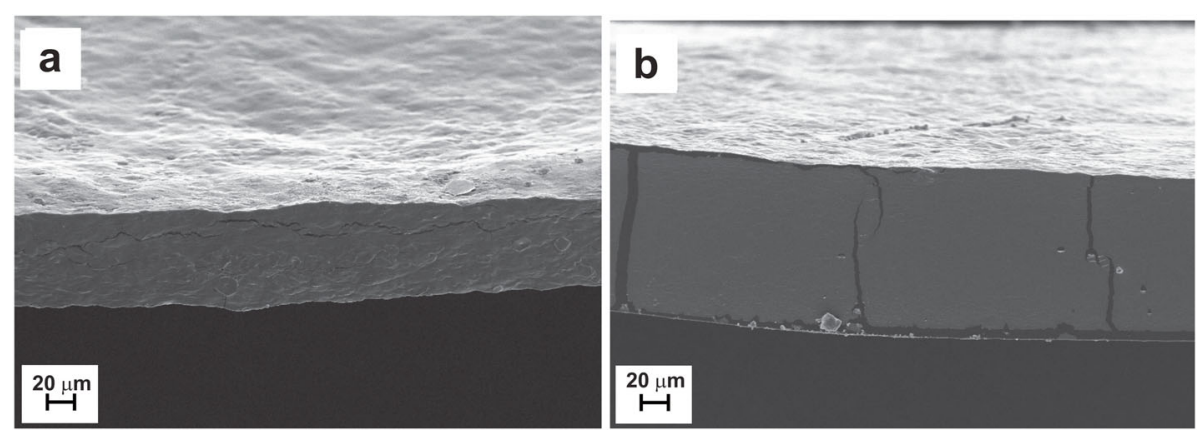

Fig. 2 SEM micrographs of TPS composite films containing a) $\mathrm{Cu}$ and b) Si-Cu particles

to the stretching of $\mathrm{OH}$ groups; bands located at 2920 and $2950 \mathrm{~cm}^{-1}$, associated to $\mathrm{CH}$ and $\mathrm{CH}_{2}$; bands at 1168 , 1082 and $984 \mathrm{~cm}^{-1}$, due to vibrations of the $-\mathrm{C}-\mathrm{O}-\mathrm{C}$ bonds in glucose; and signals at 931, 861, 771, 714, 608 and $575 \mathrm{~cm}^{-1}$ ascribed to the piranosic ring. Comparing the spectra of TPS/Cu and TPS/Si-Cu with the corresponding to TPS, no significant differences could be observed mainly due to the low concentration of particles in the TPS matrix.

Films optical properties, which include luminosity, color, and transparency, are relevant not only for the materials application but also for a commercial point of view. Luminosity and color parameters of TPS films containing copper particles are schematically represented in Fig. 3. In accordance with Labrecque and Milne [34], packaging color entices and influences consumer perceptions, and it significantly affects the identification of products/ brands. Thus, films color evaluation is important for finding potential applications of these materials in food packaging. Luminosity $\left(L^{*}\right)$ of TPS films decreased significantly with the addition of $\mathrm{Cu}$ and $\mathrm{Si}-\mathrm{Cu}$ particles. $a^{*}$ and $b^{*}$ parameters increases as particles concentration increased. Similar effect was reported by Hasheminya et al. [35] for nanobiocomposites based on kefiran-carboxymethyl cellulose and copper oxide nanoparticles. These results can be attributed to the inherent color of copper particles that gives TPS films a brownish hue. Figure 4 shows the effect of $\mathrm{Cu}$ and $\mathrm{Si}-\mathrm{Cu}$ particles on TPS films transparency. As it can be observed, copper particles induced a reduction on transparency values of TPS films. Several authors stressed that the decreased visible light transmission is attributed to opacity, hindrance of light transmission, and the scattering of light by particles as well as the distribution of particles on the polymer matrix [35-37]. Generally, opaque films limiting
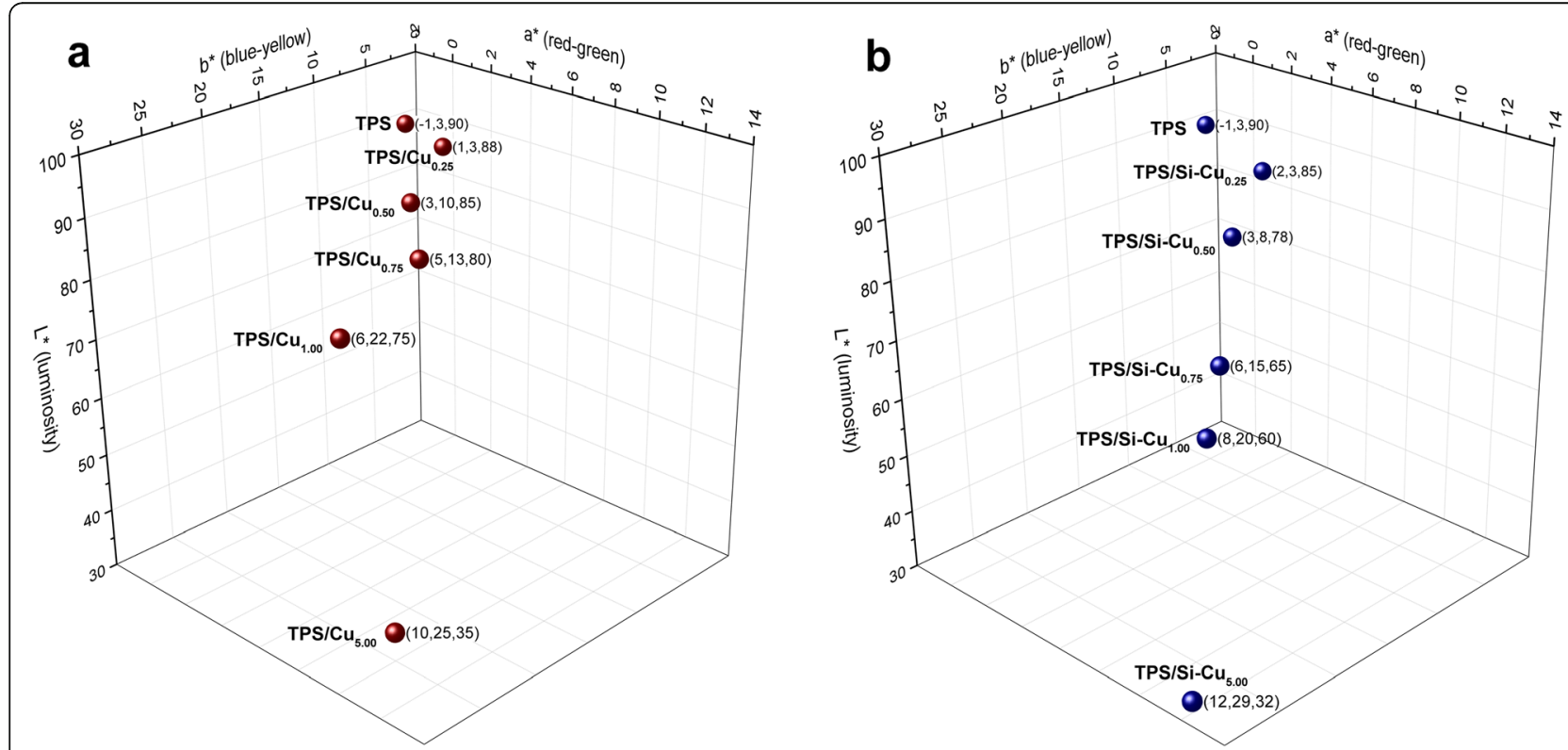

Fig. 3 Luminosity $\left(L^{*}\right)$ and color parameters ( $a^{*}$ and $b^{*}$ ) of TPS composite films containing a) Cu particles and b) Si-Cu particles. Numbers between parentheses corresponds to $L^{*}, a^{*}$, and $b^{*}$ values 

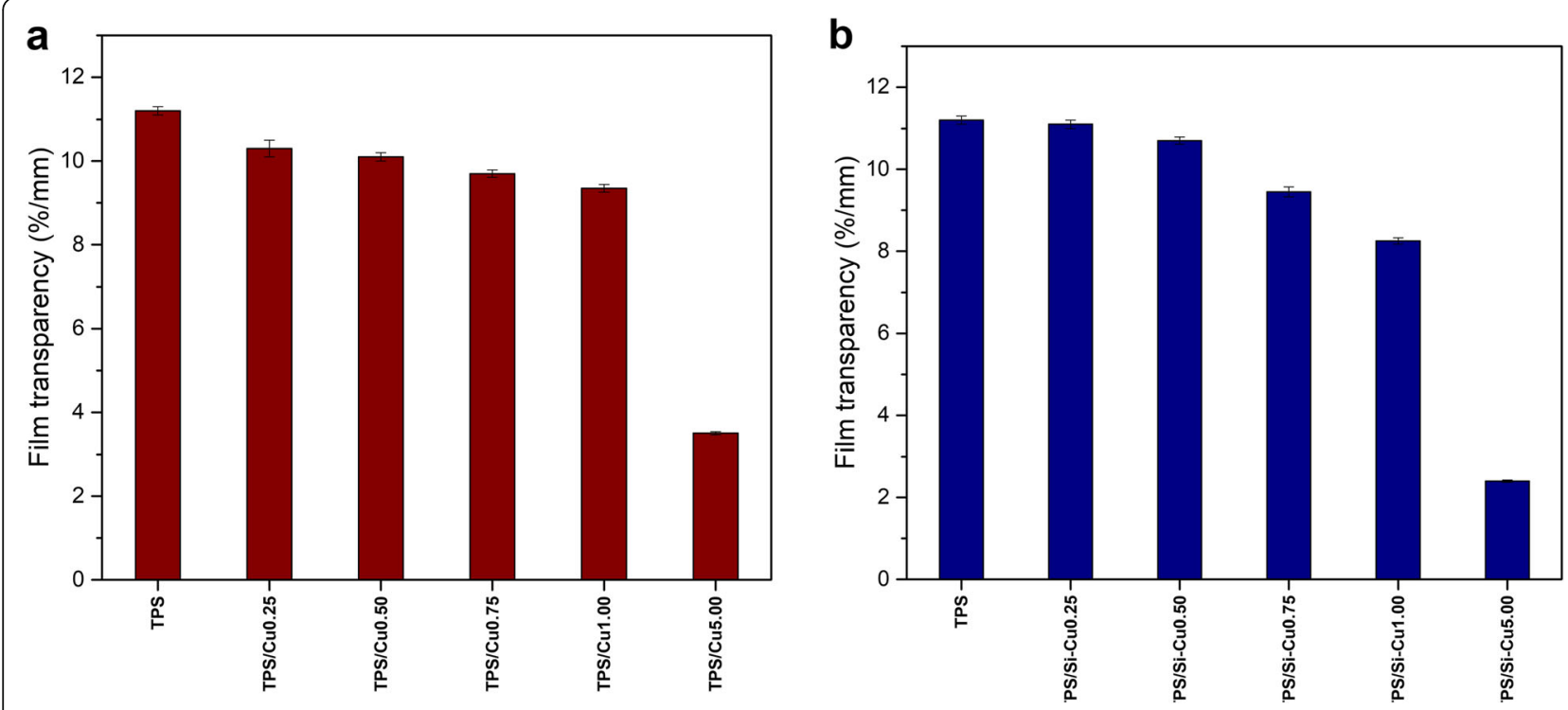

Fig. 4 Transparency of TPS composite films containing a) Cu particles and b) Si-Cu particles

visible transmission are appropriate packaging polymers, which can reduce oxidation and discoloration induced by light [38]. Taking into account the values of the optical properties, TPS films with $\mathrm{Cu}$ and $\mathrm{Si}-\mathrm{Cu}$ particles resulted in more colored and less transparent than films without copper. The intense color of composite films could affect their application as food packaging. In this sense, they could not be appropriate for developing packaging employed to offer the products to the consumer, but they could be an interesting alternative to non-biodegradable materials used as primary packaging. For some applications, films would be inside the packaging that consumers acquire and they are not visible. Then, the color of TPS composite films would not affect the acceptability of food products. On the other hand, the opacity of TPS films containing $\mathrm{Cu}$ and $\mathrm{Si}$ $\mathrm{Cu}$ particles could be an interesting feature to develop packaging for products which are susceptible to lightinduced oxidation. Considering the whole optical properties of these films, they could be considered for developing individual bags-type packaging or separating films for slices of cold cuts or fresh meat products, such as hamburgers. Regarding the proposal of using these films as primary packaging of food products, it is relevant to stress that the addition of metallic fillers probably allows a reduction in TPS hydrophilicity. This could be attributed to a lower amount of free hydroxyl groups due to physical interactions between metal particles and starch molecules. In accordance with this observation, Ji et al. [39] and Shameli et al. [40] reported the occurrence of Van der Waals forces between silver nanoparticles and hydroxyl groups of biopolymers such as starch and poly (lactic acid), respectively. Since similar interactions may take place in TPS composites containing copper particles, the reduced hydrophilicity of obtained films could allow their used as primary food packaging.

Mechanical properties of films are important to ensure integrity during transportation, handling, and storage of packaged foods [41]. Particularly, if these composite films will be used to obtain individual bags or separating films, it is important that they are tough and flexible. From some preliminary assays, it was observed that the low assayed particles concentrations (0.25 and $0.50 \%)$ did not have a significantly effect on TPS mechanical properties; therefore, results included in this work correspond to TPS films containing $0,0.75,1$ and $5 \% \mathrm{Cu}$ and $\mathrm{Si}-\mathrm{Cu}$ particles. Stress-strain curves of TPS and composites films showed that their mechanical behavior corresponds to ductile materials (Figure S2). The effect of copper particles on the mechanical properties of TPS films is presented in Fig. 5. Regarding maximum tensile strength, $\mathrm{Cu}$ and $\mathrm{Si}-\mathrm{Cu}$ particles addition at 0.75 and $1 \%$ increased this mechanical property, but this effect was not significative (Fig. 5a). Whilst, when it was incorporated $5 \% \mathrm{Cu}$ and $\mathrm{Si}-\mathrm{Cu}$ particles, maximum tensile strength had an increment of 13 and 28\%, respectively. This increment in maximum tensile strength is an indication that copper particles act as reinforcing agent of the TPS matrix. Accordingly, Ortega et al. [42] reported analogous results for composite starch films containing silver nanoparticles synthesized by an environmentally friendly method. On the other hand, composites containing $0.75,1$, and $5 \%$ copper particles presented elongation at break values notably lower than TPS films, regardless if particles were naked or coated with silica (Fig. 5b). Adding $0.75,1$, and $5 \% \mathrm{Cu}$ particles produce a reduction of 19,33 , and $68 \%$ in elongation at break, 

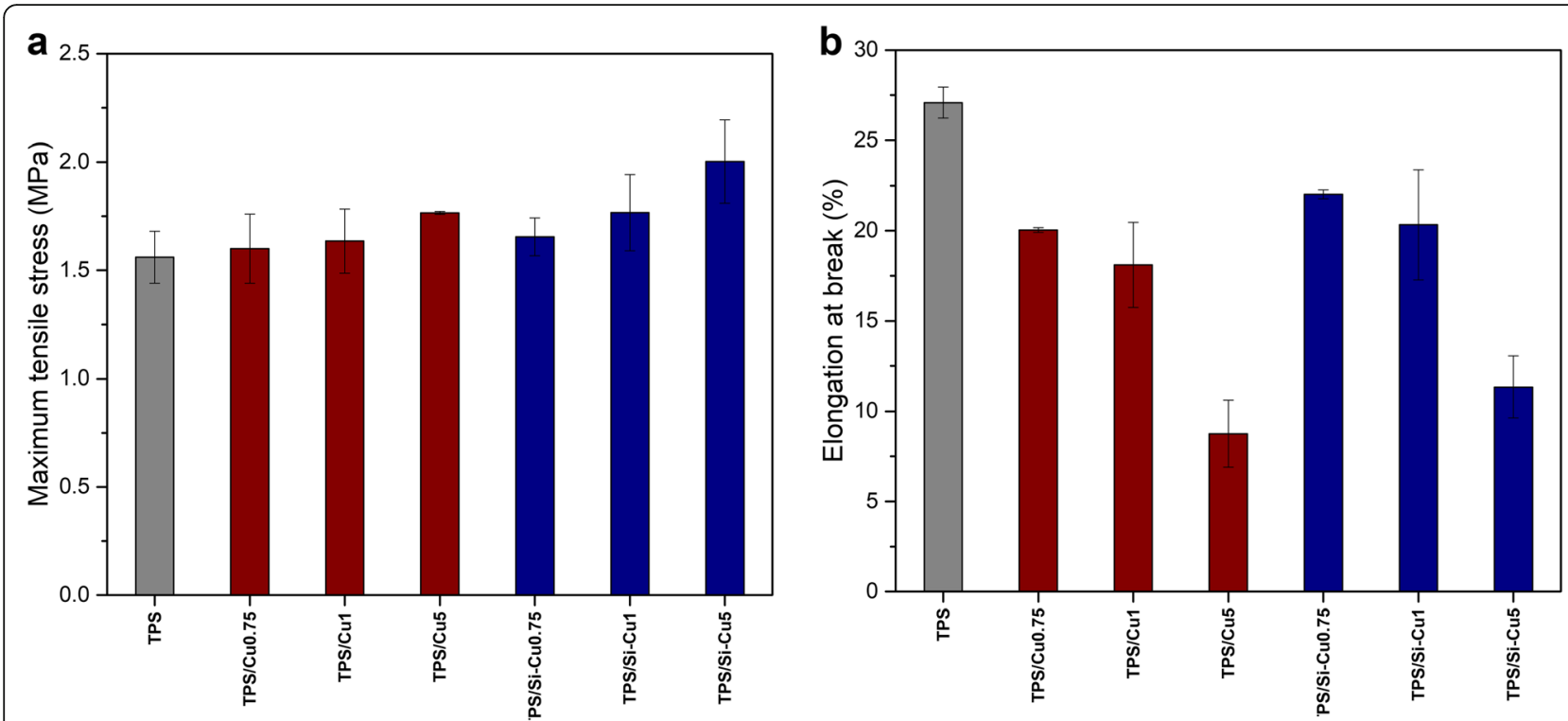

Fig. 5 Mechanical properties of TPS films containing Cu and Si-Cu particles at 1 and 5\%: a) maximum tensile strength and b) elongation at break

respectively. Meanwhile $0.75,1$, and $5 \%$ of $\mathrm{Si}-\mathrm{Cu}$ particles decreased 15, 25, and 58\% elongation at break values, respectively. This behavior is mainly due to particles that may act as stress concentrators resulting in a reduction in films elongation at break. Adding copper particles to TPS films at 1 and 5\%, despite more tough materials were developed, especially with $5 \%$, they resulted less ductile and flexible. It is important to note that ductility is a relevant mechanical issue for film applications since it determines the degree of allowable material deformation up to fracture [33]. Accordingly, the loss of flexibility might be a limitation if these materials will be use to obtain individual bags or separating films as primary food packages, so lower copper particles concentrations than $1 \%$ are recommended to manufacture these films.

\section{Antimicrobial activity assays}

From composite films characterization, it was demonstrated that adding copper particles to TPS at concentrations higher than $1 \%$, quite pigmented and not very flexible films were obtained. Therefore, antimicrobial assays were carried out only with composite films containing copper particles up to $0.75 \%$. On the other hand, if the proposal is to use these composite films to develop primary packaging which will be in contact with meat products, it is important to test some of the main microorganisms responsible of foodborne diseases. According to Omer et al. [43], one of the organisms causing most reported meat-related outbreaks is verotoxin-producing E. coli (VTEC); meanwhile $S$. aureus is other bacteria linked to meat-associated diseases, but less frequent. Therefore, TPS composites with $0,0.25,0.50$, and $0.75 \%$
$\mathrm{Cu}$ and $\mathrm{Si}-\mathrm{Cu}$ particles were assayed to evaluate their antimicrobial capacity against $E$. coli and $S$. aureus.

Antimicrobial assays results are shown in Table 1. As it can be observed, TPS/Cu and TPS/Si-Cu samples showed antimicrobial activity against both Grampositive (S. aureus) and Gram-negative (E. coli) bacteria; meanwhile TPS films without copper particles did not show this functional property. All composites films evidenced $\mathrm{R}(\log )$ values above 2 , regardless of particles type and concentration. This is the value required by the JIS [44] to consider a material as an effective antimicrobial. Thus, no significant differences were detected between antimicrobial capacity of TPS films with naked or coated copper nor with the different particle concentrations assayed. This could be because of the minimal antimicrobial concentration was reached in all the studied samples. These results suggested that the improvement in particles stability by silica coating did not reduce their antimicrobial effect.

Table 1 Antimicrobial activity of TPS composite films containing Cu and Si-Cu particles against S. aureus and E. coli

\begin{tabular}{|c|c|c|c|c|c|c|}
\hline \multirow[t]{2}{*}{ Sample } & \multicolumn{3}{|l|}{ S. aureus } & \multicolumn{3}{|l|}{ E. coli } \\
\hline & CFU/mL & $\mathrm{D} \%$ & $R(\log )$ & $\mathrm{CFU} / \mathrm{mL}$ & $\mathrm{D} \%$ & R (log) \\
\hline TPS & $2.6 \times 10^{6}$ & - & - & $1.6 \times 10^{7}$ & - & - \\
\hline $\mathrm{TPS} / \mathrm{Cu}_{0.25}$ & 60 & 99.998 & 4.6 & $2.6 \times 10^{4}$ & 99.838 & 2.8 \\
\hline $\mathrm{TPS} / \mathrm{Cu}_{0.50}$ & 32 & 99.999 & 4.9 & $4.0 \times 10^{3}$ & 99.975 & 3.6 \\
\hline $\mathrm{TPS} / \mathrm{Cu}_{0.75}$ & 18 & 99.999 & 5.2 & $1.3 \times 10^{4}$ & 99.919 & 3.1 \\
\hline TPS/Si-Cu 0.25 & 77 & 99.997 & 4.5 & $7.3 \times 10^{3}$ & 99.954 & 3.3 \\
\hline TPS/Si-Cu 0.50 & 100 & 99.996 & 4.4 & $4.0 \times 10^{3}$ & 99.975 & 3.6 \\
\hline TPS/Si-Cu & 24 & 99.999 & 5.0 & $1.3 \times 10^{3}$ & 99.999 & 5.1 \\
\hline
\end{tabular}




\section{Copper release}

The use of antimicrobial packaging increases food safety [45] and minimize the addition of synthetic additives directly to food [46]. Besides, some antimicrobial agents confer unpleasant sensory characteristics to food products and additives incorporation into packaging avoids this issue [47]. Antimicrobials should exert their action on the food surface, where microbial contamination is more intense [48]. Coma [49] stressed that additives incorporation to package materials allows a gradual release of them on the food surface, prolonging the time of action/protection. For that reason, it is relevant to evaluate the migration or release capacity of the additive from the package in order to determine if its concentration on food surface is the minimum inhibitory concentration to different microorganisms responsible for foodborne diseases and if it is below the maximum level allowed by the legislation. Several factors may affect active compounds released from biopolymer films, being the most relevant the concentration gradient of the antimicrobial, active agent characteristics, and the matrix nature [26]. In this work, water was selected as a simulant of aqueous foods, evaluating the migration capacity of $\mathrm{Cu}$ and $\mathrm{Si}-\mathrm{Cu}$ particles from TPS matrix. The amount of released copper per gram of TPS, considering the different composites studied are shown in Table 2 . The fact that copper particles have migrated from TPS films, independently if they are naked or coated, to the aqueous medium could be attributed to the quick water penetration into to the starch-glycerol matrix, allowing the diffusion of the active compounds to the simulant. Similar explanation was given by Piñeros-Hernandez et al. [50] for the release of rosemary extracts from cassava starch films to an aqueous medium. As it can be observed, released copper from TPS/Si-Cu films was significantly lower than the amount released from TPS/Cu composites. This outcome reinforced the idea that silica coating increased particles stability, diminishing copper migration

Table 2 Released copper from TPS composite films containing $\mathrm{Cu}$ and $\mathrm{Si}-\mathrm{Cu}$ particles to water and copper concentration in the simulant aqueous medium

\begin{tabular}{lll}
\hline Sample & $\begin{array}{l}\text { Released Cu } \\
\left(\mathrm{ng} \mathrm{Cu}^{2+} / \mathrm{g} \text { TPS }\right)\end{array}$ & $\begin{array}{l}\text { Cu concentration in } \\
\text { water }(\mathrm{mg} / \mathrm{L})\end{array}$ \\
\hline $\mathrm{TPS} / \mathrm{Cu}_{0.25}$ & $34.4 \pm 9.1$ & $245.8 \pm 44.2$ \\
$\mathrm{TPS} / \mathrm{Cu}_{0.50}$ & $34.3 \pm 4.6$ & $257.6 \pm 39.8$ \\
$\mathrm{TPS} / \mathrm{Cu}_{0.75}$ & $41.4 \pm 2.1$ & $273.7 \pm 28.5$ \\
$\mathrm{TPS} / \mathrm{Si}-\mathrm{Cu}_{0.25}$ & $5.1 \pm 0.7$ & $35.8 \pm 14.1$ \\
$\mathrm{TPS} / \mathrm{Si}-\mathrm{Cu}_{0.50}$ & $6.6 \pm 0.5$ & $44.8 \pm 6.1$ \\
$\mathrm{TPS} / \mathrm{Si}-\mathrm{Cu}_{0.75}$ & $4.6 \pm 1.8$ & $55.9 \pm 14.8$ \\
\hline
\end{tabular}

from the film to surrounding aqueous media. The concentration of leached $\mathrm{Cu}$ was below the maximum concentration allowed in drinking water by the Codex Alimentarius [51, 52]. On the other hand, not many data were found in the literature regarding the minimum inhibitory concentration for the tested microorganisms ( $E$. coli and $S$. aureus) exposed to copper particles. One of the few reported values is the one determined by Bondarenko et al. [53] who studied the use of different nanoparticles to fight the growth of bacteria, fungi, and algae. These authors stressed that the minimum inhibitory concentration for bacteria was $200 \mathrm{mg} / \mathrm{L}$ for $\mathrm{CuO}$ nanoparticles. $\mathrm{Cu}$ particles concentrations in the assayed aqueous simulant resulted higher than the corresponding values for $\mathrm{Si}-\mathrm{Cu}$ particles, in accordance with migration results. Besides, naked particles concentration in the aqueous medium was above the minimum inhibitory concentration value given by Bondarenko et al. [53], making these composite materials suitable for food packaging applications.

\section{Conclusions}

Active films were obtained from thermoplastic corn starch containing copper particles as antimicrobial agent at concentrations up to $5 \%$. Two kinds of $\mathrm{Cu}$ particles were used, naked copper nanoparticles and silica coated copper microparticles. Despite both fillers were well-dispersed within TPS, coated particles resulted less compatible with starch matrix, leading to some microstructural defects on composite matrices. Obtained films presented a brownish hue and a slight opacity, which increased with particles concentration. These optical properties make these composites suitable to obtain primary packaging which could be found inside the packages that consumers acquire, especially for food products susceptible to be degraded by light exposition. Although both kinds of particles acted as reinforcement agents of TPS, mainly at 1 and 5\%, their presence decreased films elongation at break. The loss of ductility could limit the application of the composites with high particles concentrations, mainly in food packaging. Composites containing $\mathrm{Cu}$ and $\mathrm{Si}-\mathrm{Cu}$ particles at concentrations between 0.25 to $0.75 \%$ presented antimicrobial activity against $E$. coli and $S$. aureus and both types of particles migrated from the starch matrix to an aqueous food simulant medium. The amount of released copper led to a naked particles concentration in the simulant medium higher than the minimum inhibitory concentration for bacteria. Taking into account the obtained results, TPS composites with $\mathrm{Cu}$ and $\mathrm{Si}-\mathrm{Cu}$ particles up to $0.75 \%$ could be appropriate to develop primary packaging such as individual type-bags or separating films, especially for fresh meat products. 


\section{Supplementary information}

Supplementary information accompanies this paper at https://doi.org/10. 1186/s42252-020-00009-7.

Additional file 1: Figure S1. FT-IR spectra of TPS films containing Cu and $\mathrm{Si}-\mathrm{Cu}$ particles at different concentrations. Figure S2. Stress-strain curves of TPS films containing a) Cu and b) Si-Cu particles at 0,75, 1, and $5 \%$.

\section{Abbreviations}

TPS: Thermoplastic Starch; SEM: Scanning Electron Microscopy; ATRFTIR: Diamond Attenuated Total Reflectance - Fourier Transform Infrared Spectroscopy; Cu: Copper particles; Si-Cu: Silica coated copper particles; TPS/ $\mathrm{Cu}_{*}$ : Composite based on thermoplastic starch and copper particles (\# corresponds to the particles concentration in the composite); TPS/Si $\mathrm{Cu}_{*}$ : Composite based on thermoplastic starch and silica coated copper particles (\# corresponds to the particles concentration in the composite); $\sigma_{\mathrm{m}}$ : Maximum tensile strength; $\varepsilon_{\mathrm{b}}$ : Elongation at break; CFU: Colony Forming Unit; LD: Laser Diffraction

\section{Acknowledgements}

The authors would like to thank the financial support of the Universidad Nacional de Buenos Aires, Universidad Nacional del Sur, and Agencia Nacional de Promoción Científica y Tecnológica (ANPCyT).

\section{Authors' contributions}

OVL, MEV, GJC, and MAV design of the work; OVL and MEV the acquisition and analysis; OVL, MEV, GJC, and MAV interpretation of data; OVL and MEV have drafted the work; GJC and MAV revised it. It is important to highlight that OVL and MEV have contributed in the same way in this article, so both of them could be considered first authors. The author(s) read and approved the final manuscript

\section{Funding}

This work was supported with grants from Universidad de Buenos Aires (UBACYT 20020170100125BA), Universidad Nacional del Sur (PGI 24/M154) and Agencia Nacional de Promoción Científica y Tecnológica (PICT 20161997 and PICT 2014-2410)

\section{Availability of data and materials}

All data generated or analyzed during this study are included in this published article [and its supplementary information files].

\section{Competing interests}

The authors declare that they have no competing interests.

\section{Author details}

'Planta Piloto de Ingeniería Química, PLAPIQUI (UNS-CONICET), Camino La Carrindanga Km. 7, 8000 Bahía Blanca, Argentina. ²Departamento de Química Analítica y Fisicoquímica, Facultad de Farmacia y Bioquímica, Universidad de Buenos Aires (UBA), Junín 956, C1113AAD Buenos Aires, Argentina. ${ }^{3}$ Instituto de Química y Metabolismo del Fármaco (IQUIMEFA), CONICET - Universidad de Buenos Aires (UBA), Buenos Aires, Argentina. ${ }^{4}$ Departamento de Ciencias Básicas, Universidad Nacional de Luján (UNLu), Ruta 5 y 7, Luján, Buenos Aires, Argentina. ${ }^{5}$ Departamento de Ingeniería Química, Universidad Nacional del Sur, Av. Alem 1253, 8000 Bahía Blanca, Argentina.

Received: 3 June 2020 Accepted: 26 July 2020

Published online: 31 July 2020

References

1. I. Var, S. Uzunlu, in Active antimicrobial food packaging, ed. by I. Var, S. Uzunlu. (IntechOpen, London, 2018), p. 1

2. N. Mlalila, D.M. Kadam, H. Swai, A. Hilonga, J. Food Sci. Technol. 53(9), 3395 (2016)

3. S. Yildirim, B. Röcker, M.K. Pettersen, J. Nilsen-Nygaard, Z. Ayhan, R. Rutkaite, T. Radusin, P. Suminska, B. Marcos, V. Coma, Compr. Rev. Food Sci. Food Saf. 17(1), 165 (2017)

4. U. Siripatrawan, P. Kaewklin, Food Hydrocoll. 84, 125 (2018)

5. A.M. Khaneghah, S.M.B. Hashemi, S. Limbo, Food Bioprod. Process. 111, $1(2018$
6. P. Scarfato, E. Avallone, M.R. Galdi, L. Di Maio, L. Incarnato, Polym. Compos 38, 981 (2017)

7. R. Bodirlau, C.A. Teaca, I. Spiridon, Compos. Part B Eng. 44, 575 (2013)

8. T. de Moraes Crizel, A. de Oliveira Rios, V.D. Alves, N. Bandarra, M. MoldãoMartins, S.H. Flôres, Food Hydrocoll. 74, 139 (2018)

9. E. Mendes, R. Piletti, T. Barichello, C. Oliveira, C. Kniess, E. Angioletto, H. Riella, M. Fiori, Mater. Sci. Eng. C 32, 1518 (2012)

10. I. Thomé, V. Dagostin, R. Piletti, C. Pich, H. Riella, E. Angioletto, M. Fiori, Mater. Sci. Eng. C 32, 263 (2012)

11. M.A. Fiori, P. Marcos Marques, M. da Silva, A.M. Bernardin, H.G. Riella, E. Angioletto, Mater. Sci. Eng. C 29, 1569 (2009)

12. M. Zanetti, T.K. Carniel, F. Dalcanton, R.S. dos Anjos, H. Gracher Riella, P.H.H. de Araújo, D. de Oliveira, M.A. Fiori, Trends Food Sci. Technol. 81(51) (2018)

13. H. Palza, R. Quijada, K. Delgado, J. Bioact. Compat. Polym. 30, 366 (2015)

14. S.F. Thomas, P. Rooks, F. Rudin, S. Atkinson, P. Goddard, R. Bransgrove, P.T. Mason, M.J. Allen, PLoS One 9, e96225 (2014)

15. Z. Chen, H. Meng, G. Xing, C. Chen, Y. Zhao, G. Jia, T. Wang, H. Yuan, C. Ye, F. Zhao, Z. Chai, C. Zhu, X. Fang, B. Ma, L. Wan, Toxicol. Lett. 163, 109 (2006)

16. EFSA, Guidance on the risk assessment of the application of nanoscience and nanotechnologies in the food and feed chain. EFSA J. (2011), pp. 1-36

17. WHO, Trace Elements in Human Nutrition and Health (World Health Organization, Geneva, 1996)

18. EFSA, Conclusion regarding the peer review of the pesticide risk assessment of the active substance Copper (I), copper (II) variants namely copper hydroxide, copper oxychloride, tribasic copper sulphate, copper (I) oxide, Bordeaux mixture. EFSA J. 187(0) (2008), pp. 1-101

19. J.C. Hannon, J.P. Kerry, M. Cruz-Romero, S. Azlin-Hasim, M. Morris, E. Cummins, E. Food Chem. Toxicol. 95, 128 (2016)

20. C. Medina-Jaramillo, O. Ochoa-Yepes, C. Bernal, L. Famá, Carbohydr. Polym. 176, 187 (2017)

21. R. Priyadarshi, J.W. Rhim, Innov. Food Sci. Emerg. Technol. 62, 102346 (2020)

22. S.A. Mohamed, M. El-Sakhawy, M.A.M. El-Sakhawy, Carbohydr. Polym. 238, $116178(2020)$

23. L.A. Castillo, O.V. López, C. López, N.E. Zaritzky, M.A. García, S.E. Barbosa, M.A Villar, Carbohydr. Polym. 95, 664 (2013)

24. F.M. Pelissari, D.C. Ferreira, L.B. Louzada, F. dos Santos, A.C. Corrêa, F.K.V. Moreira, L.H. Mattoso, in Starches for food application: chemical, technological and health properties, ed. by M. T. Pedrosa Silva Clerici, M. Schmiele. (Elsevier, Amsterdam, 2018), p. 359

25. I. Shahabi-Ghahfarrokhi, A. Babaei-Ghazvini, Int. J. Biol. Macromol. 124, 922 (2019)

26. L.A. Castillo, S. Farenzena, E. Pintos, M.S. Rodríguez, M.A. Villar, M.A. García, O V. López, Food Packag. Shelf Life 14, 128 (2017)

27. O.V. López, C.J. Lecot, N.E. Zaritzky, M.A. García, J. Food Eng. 105, 254 (2011)

28. M.D. Ninago, O.V. López, M.M.S. Lencina, M.A. García, N.A. Andreucetti, A.E. Ciolino, M.A. Villar, Carbohydr. Polym. 134, 205 (2015)

29. O.V. López, M.D. Ninago, M.M.S. Lencina, M.A. García, N.A. Andreucetti, A.E. Ciolino, M.A. Villar, Carbohydr. Polym. 126, 83 (2015)

30. J.H. Han, J.D. Floros, J. Plast. Film Sheet. 13(4), 287 (1997)

31. T.M. Tolaymat, A.M. El Badawy, A. Genaidy, K.G. Scheckel, T.P. Luxton, M. Suidan, Sci. Total Environ. 408(5), 999 (2010)

32. M.I. Din, R. Rehan, Anal. Lett. 50(1), 50 (2016)

33. L.A. Castillo, O.V. López, J. Ghilardi, M.A. Villar, S.E. Barbosa, M.A. García, Food Hydrocoll. 51, 432 (2015)

34. L.I. Labrecque, G.R. Milne, J. Acad. Mark. Sci. 40(5), 711 (2011)

35. S.M. Hasheminya, R. Rezaei Mokarram, B. Ghanbarzadeh, H. Hamishekar, H.S. Kafil, Food Packag. Shelf Life 17, 196 (2018)

36. S. Sahraee, J.M. Milani, B. Ghanbarzadeh, H. Hamishehkar, LWT Food Sci. Technol. 76, 33 (2017)

37. S. Shankar, L.F. Wang, J.W. Rhim, Carbohydr. Polym. 169, 264 (2017)

38. D. Kim, S.C. Min, J. Food Sci. 77(9), e240 (2012)

39. N. Ji, C. Liu, S. Zhang, L. Xiong, O. Sun, LWT Food Sci. Technol. 74, 311 (2016)

40. K. Shameli, M.B. Ahmad, W.M. Yunus, N.A. Ibrahim, R.A. Rahman, M. Jokar, M. Darroudi, Int. J. Nanomedicine 5, 573 (2010)

41. M. Rouhi, S.H. Razavi, S.M. Mousavi, Mater. Sci. Eng. C 71, 1052 (2017)

42. F. Ortega, L. Giannuzzi, V.B. Arce, M.A. García, Food Hydrocoll. 70, 152 (2017)

43. M.K. Omer, A. Álvarez-Ordoñez, M. Prieto, E. Skjerve, T. Asehun, O.A.A. Alvseike, Foodborne Pathog. Dis. 15, 598 (2018)

44. JIS - Japanese Industrial Standard: JIS Z 2801, (n.d.) https://www. situbiosciences.com/product/jis-z-2801-test-for-antimicrobial-activity-ofplastics/. Accessed 21 May 2020 
45. A. Rizzolo, G. Bianchi, M. Povolo, C. Anna, G. Contarini, V. Pelizzola, T.M.P. Cattaneo, Food Packag. Shelf Life 8, 41 (2016)

46. M. Moradi, H. Tajik, S. Mehdi, R. Rohani, A. Mahmoudian, LWT Food Sci. Technol. 72, 37 (2016)

47. G. da Silva Dannenberg, G.D. Funck, F.J. Mattei, W.P. Silva, A.M. Fiorentini, Innov. Food Sci. Emerg. 36, 120 (2016)

48. P. Appendini, J.H. Hotchkiss, Innov. Food Sci. Emerg. 3, 113 (2002)

49. V. Coma, Meat Sci. 78, 90 (2008)

50. D. Piñeros-Hernandez, C. Medina-Jaramillo, A. López-Córdoba, S.N. Goyanes, Food Hydrocoll. 63, 488 (2017)

51. Codex Alimentarius - Codex general standard for natural mineral waters CODEX STAN 108-1981 (2015)

52. WHO - World Health Organization, Guidelines for drinking-water quality, 3rd edn. (WHO, Geneva, 2008)

53. O. Bondarenko, K. Juganson, A. Ivask, K. Kasemets, M. Mortimer, A. Kahru, Arch. Toxicol. 87(7), 1181 (2013)

\section{Publisher's Note}

Springer Nature remains neutral with regard to jurisdictional claims in published maps and institutional affiliations.

\section{Submit your manuscript to a SpringerOpen ${ }^{\circ}$ journal and benefit from:}

- Convenient online submission

- Rigorous peer review

- Open access: articles freely available online

- High visibility within the field

- Retaining the copyright to your article

Submit your next manuscript at $\boldsymbol{\nabla}$ springeropen.com 